Article

\title{
Biocatalytic Pickering Emulsions Stabilized by Lipase-Immobilized Carbon Nanotubes for Biodiesel Production
}

\author{
Lihui Wang ${ }^{1,2}$, Xinlong Liu ${ }^{2}$ (D), Yanjun Jiang ${ }^{1, *}$, Liya Zhou ${ }^{1}$, Li Ma ${ }^{1}$, Ying $\mathrm{He}^{1}{ }^{1}$ \\ and Jing Gao ${ }^{1, *}$ \\ 1 School of Chemical Engineering, Hebei Unive*rsity of Technology, No. 8 Guangrong Road, \\ Hongqiao District, Tianjin 300130, China; wanglihui81@yeah.net (L.W.); liyazhou@hebut.edu.cn (L.Z.); \\ malihgd@yeah.net (L.M.); heying1980@hebut.edu.cn (Y.H.) \\ 2 Department of Biochemical Engineering, Tianjin Modern Vocational Technology College, \\ No. 3 Yaguan Road, Jinnan District, Tianjin 300350, China; liux188@yeah.net \\ * Correspondence: yanjunjiang@hebut.edu.cn (Y.J.); jgao@hebut.edu.cn (J.G.); Tel.: +86-22-60204293 (J.G.)
}

Received: 10 October 2018; Accepted: 21 November 2018; Published: 27 November 2018

\begin{abstract}
Biodiesel is a promising renewable energy source that can replace fossil fuel, but its production is limited by a lack of high-efficiency catalysts for mass production and popularization. In this study, we developed a biocatalytic Pickering emulsion using multiwall carbon nanotube-immobilized Candida antarctica lipase B (CALB@PE) to produce biodiesel, with J. curcas L. seed oil and methanol as substrates. The morphology of CALB@PE was characterized in detail. A central composite design of the response surface methodology (CCD-RSM) was used to study the effects of the parameters on biodiesel yield, namely the amount of J. curcas L. seed oil (1.5 g), molar ratio of methanol to oil (1:1-7:1), CALB@PE dosage (20-140 mg), temperature $\left(30-50{ }^{\circ} \mathrm{C}\right)$, and reaction time $(0-24 \mathrm{~h})$. The experimental responses were fitted with a quadratic polynomial equation, and the optimum reaction conditions were the methanol/oil molar ratio of 4.64:1, CALB@PE dosage of $106.87 \mathrm{mg}$, and temperature of $34.9^{\circ} \mathrm{C}$, with a reaction time of $11.06 \mathrm{~h}$. A yield of $95.2 \%$, which was basically consistent with the predicted value of $95.53 \%$, was obtained. CALB@PE could be reused up to 10 times without a substantial loss of activity. CALB@PE exhibited better reusability than that of Novozym 435 in the process of biodiesel production.
\end{abstract}

Keywords: Pickering emulsion; multiwalled carbon nanotubes (MWCNTs); biodiesel; response surface methodology

\section{Introduction}

Biodiesel is widely regarded as a good substitute for fossil diesel, due to its unique characteristics, namely renewability, biodegradability, nontoxicity, and clean combustion [1-3]. Based on an overview of previous studies, the most cost-efficient method for the production of biodiesel with relatively high quality is the transesterification of oils and fats with short-chain alcohols catalyzed by chemicals (bases) [2]. The chemical-catalyzed method for biodiesel production has been industrially adopted due to its low reaction time and high yield [4]. However, the many inherent drawbacks of this chemical-catalyzed process limit its further development, such as the high reaction temperature, high energy consumption, corrosive nature of the catalyst, and so forth [5]. Lipases that catalyze processes for biodiesel production are more economically and environmentally advantageous than the conventional chemical methods and have received increasing attention because the inherent problems associated with chemical catalysts can be addressed [6]. However, the high cost, poor reusability, and low stability of lipases hinder their wide application in industrial production process [7-9]. 
Enzyme immobilization is an efficient way to solve such problems. A suitable immobilization technique effectively improves the value of lipases in biodiesel production by enhancing their stability and enabling continuous reuse and separation. You et al. immobilized a lipase from Burkholderia cepacia on modified attapulgite by crosslinking for biodiesel production. The maximum yield of $94 \%$ was obtained under the best conditions of: $10 \mathrm{~g}$ jatropha oil, $2.4 \mathrm{~g}$ methanol (molar ratio of oil to methanol of 1:6.6) being added at $3 \mathrm{~h}$ intervals, $7 \mathrm{wt} \%$ water, $10 \mathrm{wt} \%$ immobilized lipase, temperature of $35{ }^{\circ} \mathrm{C}$, and reaction time of $24 \mathrm{~h}$ [10]. Nguyen et al. reported that a biodiesel yield of $96.18 \%$ was obtained at a temperature of $26^{\circ} \mathrm{C}$, methanol/fat molar ratio of 6.33:1, enzyme (adsorbed onto resin) loading of $20 \%$, and reaction time of $9.48 \mathrm{~h}$ [11]. Multiwalled carbon nanotubes (MWCNTs) have been demonstrated as being effective supports for enzyme immobilization due to their considerable advantages, including high surface area, low diffusion limitations, a high enzyme-loading amount, and high mechanical stability [12]. Enzymes can be immobilized on the surface of MWCNTs by adsorption or covalent binding, resulting in improved catalytic performance and stability. For example, in Prlainović's work [13], Candida rugosa lipase was adsorbed on unmodified MWCNTs, and 85\% of the initial enzyme activity was retained. Yan et al. [14] reported that Rhizomucor miehei lipase was covalently immobilized on magnetic MWCNTs and the obtained immobilized lipase showed improved stability and recyclability.

Since MWCNTs are small, the recovery of MWCNT-immobilized enzymes after the reaction is a difficult task. Until now, a series of particles including mesoporous silica [15], polymersomes [16], microgels [17], and carbonaceous microspheres [18] have been used to construct enzyme-containing Pickering emulsions. These reports have confirmed that the immobilization of enzymes using Pickering emulsion systems is a facile and effective means for facilitating the nanoparticle/nanobiocatalyst recovery and reaction product separation. In addition, lipases are well-known interfacially active catalysts and exhibit their catalytic abilities at the interface between the organic phase containing hydrophobic substrates and the aqueous phase. Thus, Pickering emulsions may have great potential in applications for lipase immobilization. If water-in-oil $(\mathrm{w} / \mathrm{o})$ or oil-in-water $(\mathrm{o} / \mathrm{w})$ Pickering emulsions constructed by MWCNT-immobilized Candida antarctica lipase B(CALB@MWCNTs) are developed, capsules with a shell comprising the CALB@MWCNTs particles will be formed. The lipase will be located at the surface of the micron-sized water droplets, which is involved in a continuous organic phase. At the hydrophobic-hydrophilic interface, the lipases can be activated [16]. The density difference between the water-containing capsules and the organic phase will make the capsules quickly sink to the bottom of the organic phase soon after stirring or shaking ceases, which makes recycling easier. When this biocatalytic system was used in biodiesel synthesis, the CALB@MWCNT Pickering emulsions were easily separated from the substrates and products in the organic phase. Thus, by using the CALB@MWCNT-based Pickering emulsions for catalysis in organic media, not only can the catalytic performance be improved, but the reusability can also be easily realized. However, to the best of our knowledge, there are no prior reports using CALB@MWCNT-based Pickering emulsions as a catalyst for biodiesel synthesis.

\section{Results and Discussion}

\subsection{Optimization of CALB@PE Construction}

Prior to the formation of CALB@PE, the CALB should be covalently attached onto the MWCNTs. The effect of the operating parameters was studied, and the optimum conditions were obtained and adopted as detailed in in Section 2.2. In the construction of CALB@PE, the effect of major parameters, such as CALB@MWCNT dosage and emulsification time, on the performance of CALB@PE was studied.

As shown in Figure 1, the activity of CALB@PE increased from $43.55 \mathrm{U}$ to a maximum of $69.01 \mathrm{U}$ as the CALB@MWCNT concentration in the emulsions increased to $4.0 \mathrm{wt} \%$, and then decreased rapidly with further increases of dosage. This phenomenon could be explained by the changes in the 
CALB@PE droplet morphologies. At the lower concentration range (1.0-4.0 wt \%), more and more of the CALB@MWCNTs were adsorbed at the interface of the two water-oil phases and exhibited a higher catalytic capacity. The droplet size gradually decreased, and the increase of the specific surface area caused the CALB@PE activity to become higher and higher [19] (Figures S1 and S2). However, when the CALB@MWCNT dosage was greater than 4.0 wt \%, the CALB@MWCNTs exceeded the interface requirement. Excess CALB@MWCNTs were suspended in solution or formed a thick shell at the interface (see the dark shadow in Figure S2), which inhibited the mass transfer and accessibility of the enzyme in the reaction system [20]. Thus, the CALB@MWCNT dosage of $4.0 \mathrm{wt} \%$ was chosen for the subsequent experiments.

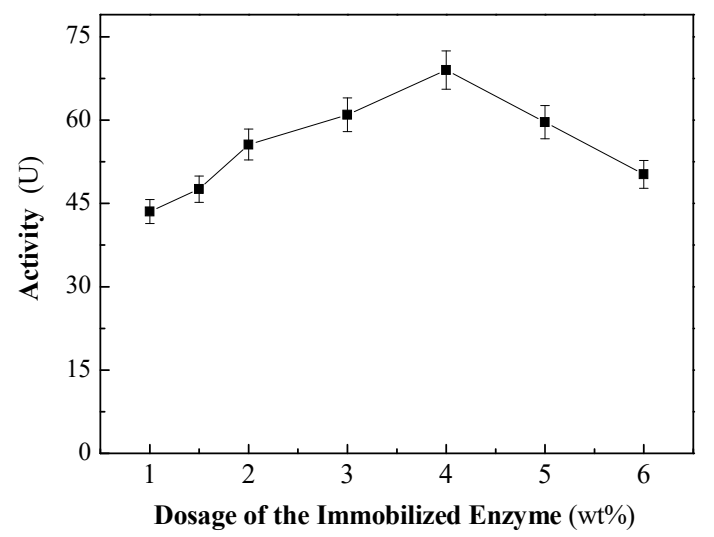

Figure 1. Effect of multiwalled carbon nanotube-immobilized Candida antarctica lipase B (CALB@MWCNT) dosage on CALB Pickering emulsion (CALB@PE) activity.

Figure 2 shows the effect of the ultrasonic emulsification time on the activity of CALB@PE. Without ultrasonic emulsification, the activity of CALB@PE was only $38.19 \mathrm{U}$ and the emulsion did not form (Figures S3 and S4). Through ultrasonic emulsifying operations, a CALB@PE with a better activity was obtained, and the highest activity $(75.71 \mathrm{U})$ was observed when the emulsification time was $10 \mathrm{~min}$. A further increase in the emulsification time led to a decrease in the activity. This was because the average particle size decreased gradually with the extended emulsification time and led to a higher interface area, which promoted the improvement of the CALB@PE activity. However, long-term ultrasonic operation ( $\geq 10 \mathrm{~min}$ ) decreased the activity of the CALB@PE through the destruction of the structure of the CALB molecules and the CALB@PE capsule [21,22]. Therefore, $10 \mathrm{~min}$ of ultrasonic emulsification was chosen for subsequent study.

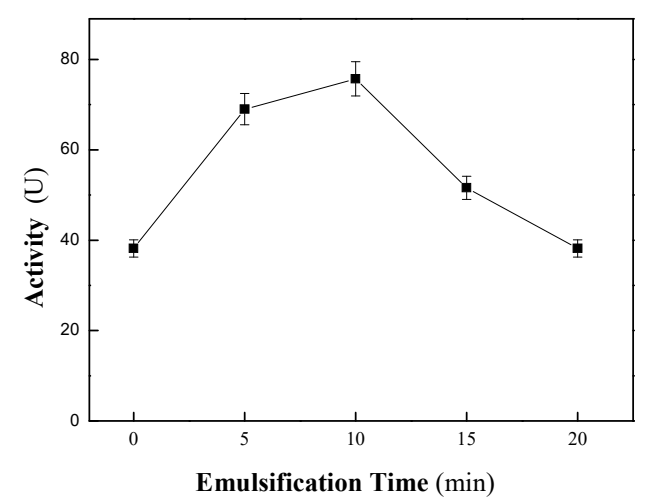

Figure 2. Effect of emulsion time on the CALB@PE activity.

The thermal stability was an important factor to evaluate the performance of CALB@PE. Herein, the thermal stability of CALB@PE was examined through catalyzing esterification after incubating CALB@PE at different temperatures for $3 \mathrm{~h}$. The initial activity of CALB@PE without heat treatment 
was defined as being $100 \%$, and the relative activity (\%) represented the ratio of the residual activity to the initial activity of each sample. As shown by Figure 3, CALB@PE showed the highest activity at $35{ }^{\circ} \mathrm{C}$. Any small temperature change led to a decrease in activity. Long-term exposure to higher temperatures than $35^{\circ} \mathrm{C}$ would damage the structure of $\mathrm{CALB}$, and then the level of destruction-and thus reduction of activity-would increase with increasing temperature [23]. Lower temperatures $\left(<35^{\circ} \mathrm{C}\right)$ would negatively affect the mass transfer rate, resulting in the reduction of activity.

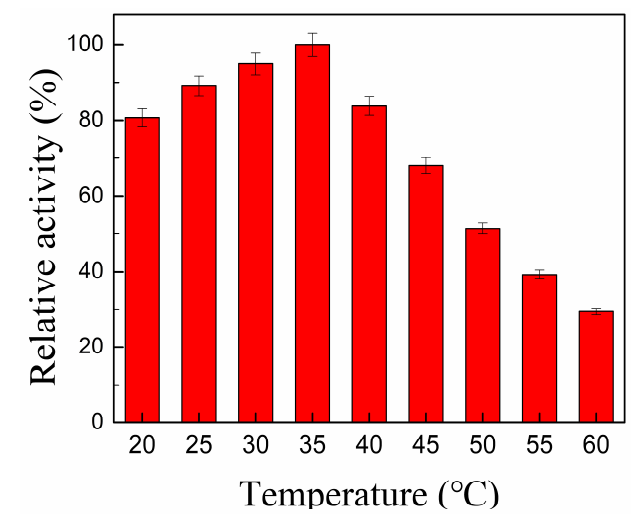

Figure 3. The thermal stability of CALB@PE.

For observing the morphology of CALB@PE easily, an agarose solution (1.5 wt \%) was employed as an aqueous core to produce Pickering emulsions. The SEM image clearly revealed that the jellified CALB@PE droplets were covered with random, closely packed CALB@MWCNTs shells (Figure 4a). The droplets were not standard spheres because of the swelling effect of the agar solution on the shell of the CALB@MWCNTs. To clearly distinguish the type of CALB@PE, fluorescein isothiocyanate-labeled dextra (FITC-Dex) and Nile red were dissolved in water and heptane, respectively. With a green emission (FITC-Dex) inside the droplets and a red emission (Nile red) outside of the droplets, the water-in-heptane Pickering emulsion ( $\mathrm{w} / \mathrm{o}$ ) was clearly identified by the confocal laser scanning microscopy (CLSM) images (Figure $4 \mathrm{~b}, \mathrm{c}$ ). The stable biphasic system could be stored unchanged for at least 150 days, which was confirmed by optical microscopy. It should be noted that the CALB@PE would be destroyed if the heptane disappeared as a result of volatilization during storage.
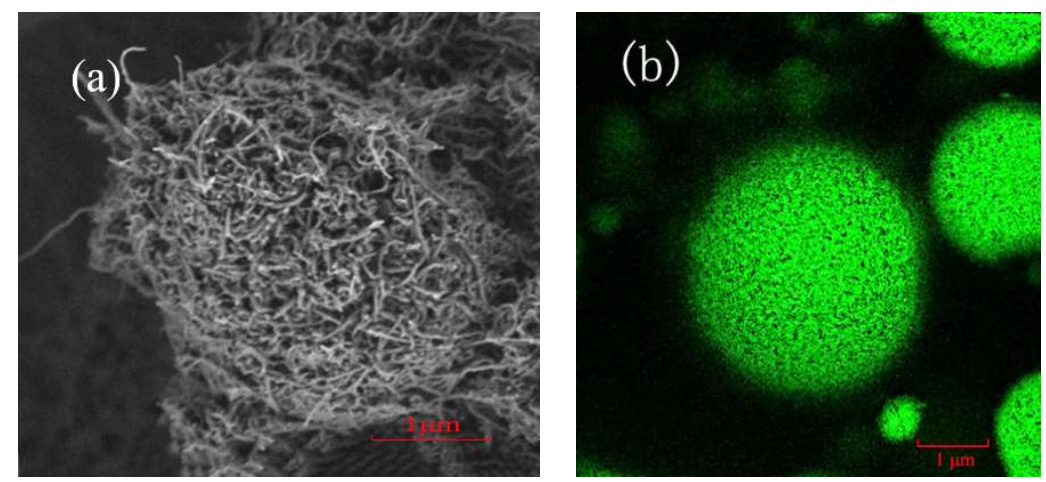

Figure 4. Cont. 


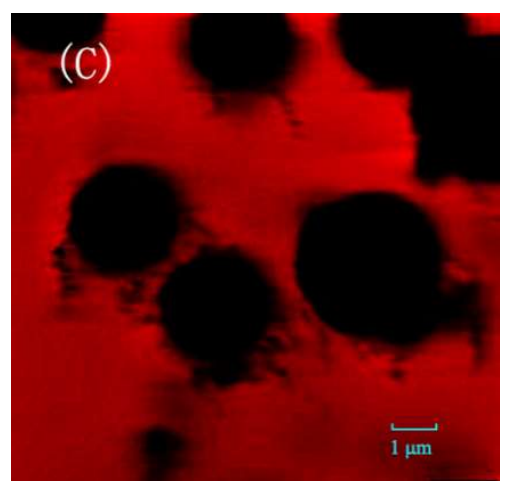

Figure 4. (a) SEM image of the jellified CALB@PE droplets; confocal laser scanning microscopy (CLSM) images of CALB@PE of FITC-Dex in water $(\mathbf{b})$ and Nile red in toluene (c), respectively.

\subsection{Optimization of the Biodiesel Production Catalyzed by CALB@PE}

To increase the biodiesel yield, we focused our attention on the optimization of four process parameters, namely the molar ratio of methanol to oil (1:1-7:1), CALB@PE dosage (20-140 mg), temperature $\left(30-50^{\circ} \mathrm{C}\right)$, and reaction time $(0-24 \mathrm{~h})[21,24,25]$. According to the experimental result measured by a single-factor experiment, response surface methodology (RSM) was employed to realize an in-depth study, and the experimental design operated by Design-Expert 8.0.6 is represented in Table 1. Based on a central composite design' (CCD), 30 reactions were carried out, and the yield of the obtained biodiesel varied greatly, from 58.24 to $95.53 \%$ (Table 2). The predicted surface plots about the relationship between the four factors and the biodiesel yield are shown in Figure 4 . The results were determined by multiple linear regressions and modeled by a polynomial quadratic equation [26]:

$$
\begin{aligned}
& \mathrm{Y}=-220.05175+24.54354 \mathrm{r}+5.70004 \mathrm{~T}+14.47302 \mathrm{t}+0.96253 \mathrm{M}-0.019667 \mathrm{rT} \\
& -0.61281 \mathrm{rt}-0.00606 \mathrm{rM}+0.13400 \mathrm{Tt}+0.00744 \mathrm{TM}-0.00131 \mathrm{tM}-1.85248 \mathrm{r}^{2} \\
& -0.10351 \mathrm{~T}^{2}-0.68248 \mathrm{t}^{2}-0.00474 \mathrm{M}^{2}
\end{aligned}
$$

Table 1. Experimental design of each selected variable for biodiesel production.

\begin{tabular}{ccccccc}
\hline Factor & Name & Unit & $\begin{array}{c}\text { Low Level } \\
(-)\end{array}$ & $\begin{array}{c}\text { High } \\
\text { Level (+) }\end{array}$ & - alpha & +alpha \\
\hline $\mathrm{r}$ & $\begin{array}{c}\text { Molar ratio of } \\
\text { methanol to seed acid }\end{array}$ & & 3 & 7 & 1 & 9 \\
$\mathrm{M}$ & CALB@PE dosage & $\mathrm{mg}$ & 80 & 140 & 50 & 170 \\
$\mathrm{~T}$ & Temperature & ${ }^{\circ} \mathrm{C}$ & 30 & 45 & 22.5 & 52.5 \\
$\mathrm{t}$ & Time & $\mathrm{h}$ & 8 & 12 & 6 & 14 \\
\hline
\end{tabular}

Table 2. Experimental design and results for biodiesel production using a central composite design of response surface methodology (CCD-RSM).

\begin{tabular}{cccccc}
\hline No. & $\begin{array}{c}\text { r (Molar Ratio of } \\
\text { Methanol to Seed Acid) }\end{array}$ & $\begin{array}{c}\text { M (CALB@PE } \\
\text { Dosage, } \mathbf{m g})\end{array}$ & $\begin{array}{c}\text { T } \\
\left.\text { (Temperature, }{ }^{\circ} \mathbf{C}\right)\end{array}$ & t (Time, h) & Yield \% \\
\hline 1 & 3 & 80 & 30 & 8 & 65.80 \\
2 & 7 & 80 & 30 & 12 & 69.00 \\
3 & 5 & 170 & 37.5 & 10 & 88.51 \\
4 & 7 & 80 & 45 & 8 & 58.24 \\
5 & 5 & 110 & 37.5 & 14 & 95.50 \\
6 & 9 & 110 & 37.5 & 10 & 59.12 \\
7 & 7 & 140 & 30 & 8 & 72.69 \\
8 & 7 & 110 & 45 & 8 & 72.01 \\
9 & 5 & & 37.5 & 6 & 71.80 \\
\hline
\end{tabular}


Table 2. Cont.

\begin{tabular}{cccccc}
\hline No. & $\begin{array}{c}\text { r (Molar Ratio of } \\
\text { Methanol to Seed Acid) }\end{array}$ & $\begin{array}{c}\text { M (CALB@PE } \\
\text { Dosage, } \mathbf{m g})\end{array}$ & $\begin{array}{c}\text { T } \\
\left.\text { (Temperature, }{ }^{\circ} \mathbf{C}\right)\end{array}$ & t (Time, h) & Yield \% \\
\hline 10 & 5 & 110 & 37.5 & 10 & 94.10 \\
11 & 3 & 80 & 45 & 12 & 80.00 \\
12 & 3 & 140 & 30 & 12 & 87.00 \\
13 & 3 & 80 & 30 & 12 & 79.00 \\
14 & 1 & 110 & 37.5 & 10 & 70.86 \\
15 & 5 & 110 & 37.5 & 10 & 94.53 \\
16 & 7 & 110 & 45 & 12 & 69.00 \\
17 & 5 & 140 & 37.5 & 10 & 93.21 \\
18 & 7 & 110 & 30 & 12 & 76.00 \\
19 & 5 & 80 & 37.5 & 10 & 94.70 \\
20 & 3 & 140 & 45 & 8 & 60.00 \\
21 & 3 & 110 & 45 & 8 & 74.00 \\
22 & 5 & 140 & 52.5 & 10 & 71.26 \\
23 & 7 & 110 & 45 & 12 & 82.92 \\
24 & 5 & 80 & 37.5 & 10 & 95.39 \\
25 & 7 & 110 & 30 & 8 & 67.00 \\
26 & 5 & 50 & 37.5 & 10 & 93.80 \\
27 & 5 & 110 & 37.5 & 10 & 66.50 \\
28 & 5 & 140 & 22.5 & 10 & 71.30 \\
29 & 5 & 140 & 30 & 8 & 75.00 \\
30 & 3 & 45 & 12 & 95.00 \\
\hline
\end{tabular}

An analysis of variance (ANOVA) was used to determine the significant parameters that influenced the yield of biodiesel (Table 3). The model F-value of 829.88, carried out by a Fisher's statistical test, implied that the model was significant, indicating that there was only a $0.01 \%$ chance that a nonsignificant "Model F-Value" could occur due to the noise. Values of "Prob > F" that were less than 0.0500 indicated that the model terms were significant. According to this, r, T, t, M, rt, rM, Tt, TM, $\mathrm{r}^{2}, \mathrm{~T}^{2}, \mathrm{t}^{2}$, and $\mathrm{M}^{2}$ were also significant model terms. A "Lack of Fit F-Value" of 0.47 implied that the lack of fit was not significant relative to the pure error. There was an $85.37 \%$ chance that a "Lack of Fit F-Value" might be more to do with noise, and a nonsignificant lack of fit was desired [27]. This implied that the model was statistically significant for the yield of biodiesel [28]. The fits of the models were evaluated by determining the coefficients $\left(R^{2}\right)$. The $R^{2}$ of the model was 0.9987 , which meant the fraction of the variation of the response was explained by the model. The predicted $R^{2}$ of 0.9954 was basically consistent with the adjusted $R^{2}$ of 0.9975 . "Adeq Precision" was used to analyze the signal-to-noise ratio. Our ratio of 85.028 was greater than 4 , indicating an adequate signal. This model could be used to navigate the design space [29]. Overall, well-fitting models for biodiesel yield were successfully established.

Table 3. ANOVA for the response surface quadratic model for the yield of biodiesel.

\begin{tabular}{ccccc}
\hline Terms & F-Value & $p$-Value (Prob $>$ F) & Value & Analysis \\
\hline Model & 829.88 & $<0.0001$ & & significant \\
$\mathrm{r}$ (Molar ratio of methanol to seed acid) & 1318.57 & $<0.0001$ & & \\
$\mathrm{M}$ (CALB@PE dosage) & 406.71 & $<0.0001$ & & \\
$\mathrm{~T}$ (Temperature) & 759.10 & $<0.0001$ & & not significant \\
$\mathrm{t}$ (Time) & 347.97 & $<0.0001$ & & \\
Lack of Fit & 0.47 & 0.8537 & & 0.9987 \\
$\mathrm{R}^{2}$ & & & 0.9975 & \\
Adjusted $\mathrm{R}^{2}$ & & & 0.9954 & \\
Predicted $\mathrm{R}^{2}$ & & & 85.028 & \\
Adequate Precision & & & 0.78 & \\
Coefficient of variation \% & & &
\end{tabular}


Figure 5 shows the 3D response plots and contour curves of the biodiesel yield, which were employed to analyze the interactions among the variables and the optimum value of each parameter for maximizing the yield of biodiesel.

In Figure 5a, the interaction effect between the methanol/oil molar ratio and the temperature on the yield of biodiesel is presented, while maintaining the other factors at their central levels. The umbrella curve revealed a strong interaction between the two factors around the ' 0 ' level, and any small change would result in a sharp drop in the yield of biodiesel [26]. The highest yield was observed for the methanol/oil molar ratio of 4.64:1 at any temperatures. The increase or decrease in the molar ratio from this value negatively affected the yield. This was because more methanol stripped off the essential water from the active site of the CALB, which deactivated the CALB. Moreover, if the addition of methanol was insufficient for the stoichiometric requirement, a lower yield of biodiesel was inevitable [29]. Similarly, it is reasonable that $34.9^{\circ} \mathrm{C}$ was chosen as the best temperature for obtaining the maximum yield. The phenomenon could be explained by the fact that a lower temperature inhibited CALB activity and a higher temperature damaged the molecular structure of CALB, leading to CALB inactivation, which is in agreement with others' studies.

Figure $5 \mathrm{~b}$ presents the effect of the methanol/oil molar ratio and the CALB@PE dosage on the yield of biodiesel, with the temperature and reaction time at their central levels. At any CALB@PE dosage (80-140 mg), the yield of biodiesel increased with the methanol/oil molar ratio. However, when the yield reached the maximum, a further increase of the methanol/oil molar ratio would lead to a reversal of the above trend. This phenomenon can be explained by the fact that CALB inactivation is caused by excessive methanol; it is well known that a high level of methanol inhibits the activity of CALB and leads to a decreased biodiesel yield. As shown in Figure $4 \mathrm{~b}$, the maximum yield of biodiesel was obtained when the methanol/oil molar ratio was 4.64:1 and the CALB@PE dosage was $106.87 \mathrm{mg}$.

Figure $5 \mathrm{c}$ shows a response surface curve obtained by plotting the yield of biodiesel against the reaction time and the CALB@PE dosage, while keeping the other factors at central levels. An increment in the biodiesel yield was observed as the CALB@PE dosage or reaction time increased, while the improvement rate slowed down when the CALB@PE dosage and time approached their maximum. At a high CALB@PE dosage level, the initial speed of the reaction was so fast that much of the substrate was consumed in a short time. A lack of substrates would inevitably lead to a slower follow-up reaction, which is in accordance with enzyme-mediator kinetics. Moreover, the influence on the increase in the biodiesel yield by raising the CALB@PE dosage became increasingly poor, but the costs were continually rising. Based on the above results and discussion, a dosage of $106.87 \mathrm{mg}$ of CALB@PE was a more appropriate option. Considering the experimental results and the time-cost tradeoff, a reaction time of $11.06 \mathrm{~h}$ was chosen.

Based on the CCD-RSM results, a confirmatory experiment was conducted and an actual yield of $95.2 \%$ was obtained, which was very close to the predicted value of $95.53 \%$. Thus, the RSM model was proven to sufficiently describe the relationship between the variable and the yield of biodiesel. Table S1 shows the comparison of the performance of CALB@PE with other enzymes in biodiesel production. In comparison with the other researchers' results, the performance of CALB@PE was satisfactory both in terms of methanol dosage, catalyst dosage, or reaction time. 

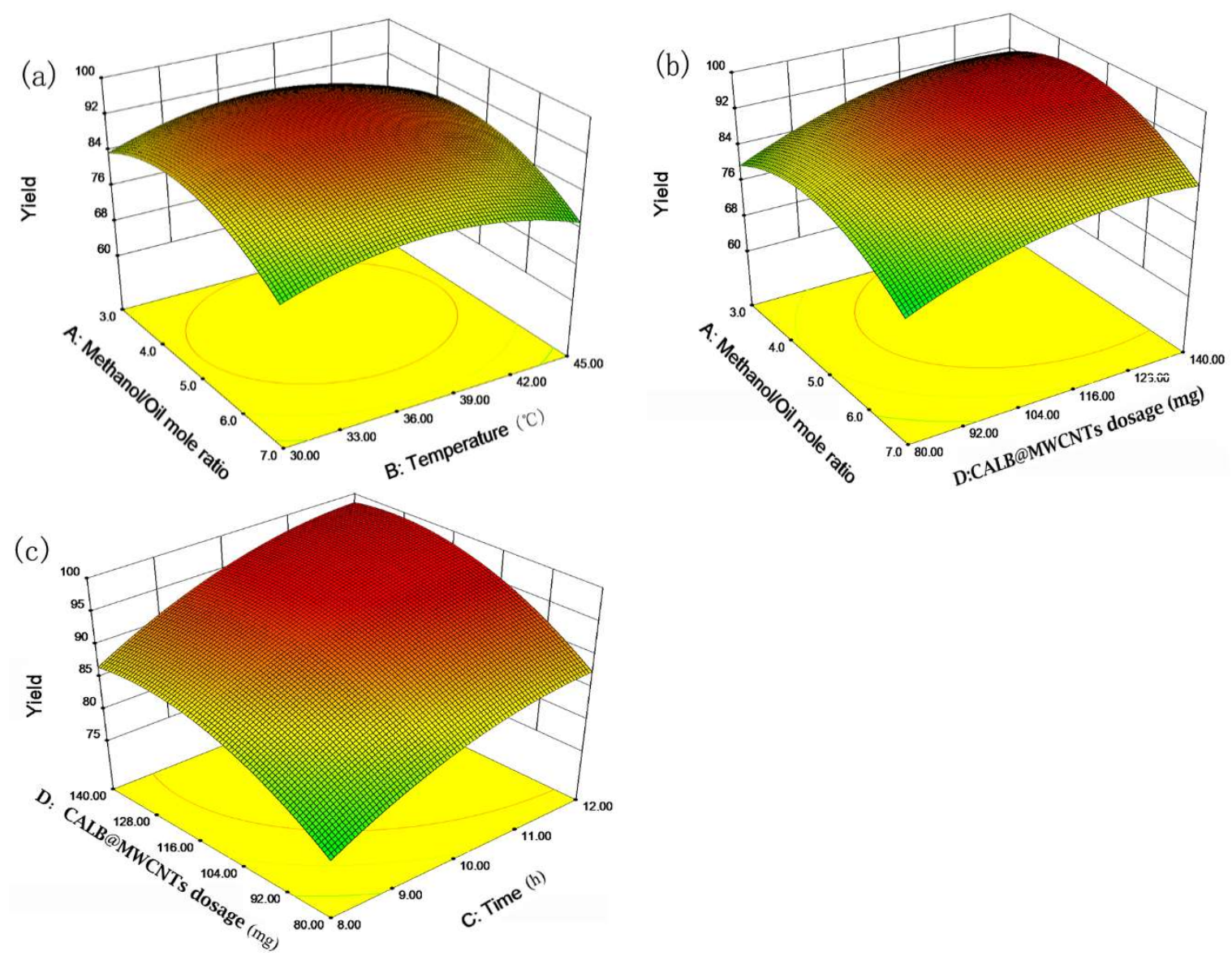

Figure 5. Response surface plots showing the effect of two parameters on the yield of biodiesel: (a) molar ratio of methanol to oil vs temperature; (b) molar ratio of methanol to oil vs CALB@PE dosage; (c) time vs CALB@PE dosage.

\subsection{Operational Stability of CALB@PE}

Catalysts that can be reused many times are preferred because they lower production costs. Therefore, the operational stability of CALB@PE was investigated over 15 cycles of biodiesel production. As shown in Figure 6, the maximum yield of biodiesel (based on oleic acid) catalyzed by CALB@PE and Novozym 435 were $94.94 \%$ and $99.91 \%$, respectively. However, the excellent performance of Novozym 435 only lasted for the first three rounds, and then decreased dramatically. In the first five catalyst reuses, the biodiesel yields with CALB@PE (90.85\%) or Novozym $435(85.42 \%)$ as a catalyst were not very different. However, the yield was only $40.73 \%$ after Novozym 435 was recycled 10 times, but was $77.51 \%$ for CALB@PE. Furthermore, the CALB@PE obtained nearly $67.43 \%$ of its initial activity after the 15th cycle. Thus, it was easily considered that the stability of CALB@PE was much better than Novozym 435 for application in biodiesel production. The explanation for this phenomenon could be summed up in three aspects: First, the crosslinking immobilization method used in CALB@PE provided better stability compared with the adsorption method used in Novozym 435 [30]. Second, the structural stability of the multiwall nanotubes used in CALB@PE was better than that of the resin used in Novozym 435. Finally, the performance of the enzyme was improved in all aspects due to the better microenvironment provided by the Pickering emulsion [31]. The slow reduction in CALB@PE activity during repeated use might be due to the accumulation of structural damage of CALB caused by multiple centrifugal demulsifications and ultrasonic emulsifications in the cyclic utilization. 


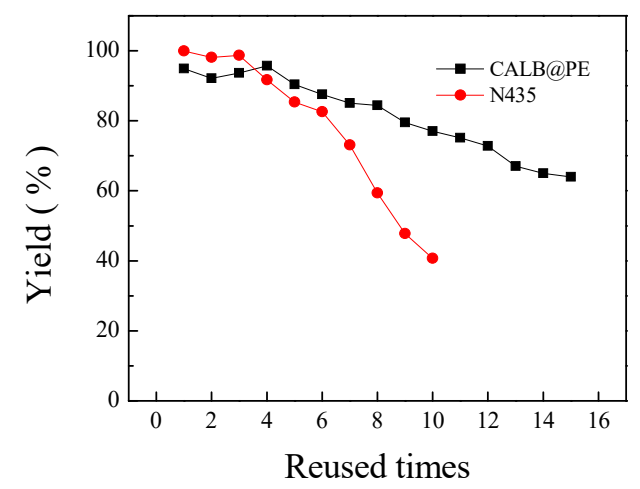

Figure 6. Reusability of CALB@PE and Novozym 435 (N435) in biodiesel production.

\section{Materials and Methods}

\subsection{Materials}

$\mathrm{NH}_{2}$-functionalized multiwalled carbon nanotubes (MWCNTs-NH$H_{2}$ ) (purity: $>95 \%$; $\mathrm{NH}_{2}$ content: 0.45 wt \%) were purchased from Chengdu Organic Chemicals Co., Ltd. (Chengdu, China). The Candida antarctica lipase B (16.7 mg protein/mL) and Novozym 435 were purchased from Beijing Cliscent Technology Co., Ltd. Fluorescein isothiocyanate labeled dextran (FITC-Dex) and Nile Red were obtained from J\&K Scientific Ltd. (Beijing, China). Glutaraldehyde, oleic acid, methanol, 1-hexanol, and hexanoic acid were purchased from Tianjin Chemical Corporation (Tianjin, China). J. curcas L. seed oil (palmitic acid: 13.6-15.4\%, stearic acid: 6.5-6.7\%, oleic acid: $36.1-41.5 \%$, linoleic acid: 35.2-42.8\%, other acids: $0.9 \%$ ) was obtained from Ruifeng Plantation Companies, Guizhou Province, China. All standard materials for gas chromatography (GC) were purchased from Tokyo Chemical Industry Co., Ltd (Tokyo, Japan). All other chemicals and reagents were of analytical grade.

\subsection{Preparation of Pickering Emulsions}

For the activation of the carbon nanotubes, MWCNTs- $\mathrm{NH}_{2}(100 \mathrm{mg})$ was suspended in $5 \mathrm{~mL}$ of a glutaraldehyde solution $(0.2 \%, 10 \mathrm{mM}$ phosphate buffered saline, $\mathrm{pH} 7.0)$ and was magnetically stirred for $1 \mathrm{~h}$ at $30{ }^{\circ} \mathrm{C}$. The suspension was then centrifuged, and the solid was washed with distilled water three times. After activation, the activated MWCNTs-NH2 were dispersed into $2 \mathrm{~mL}$ of CALB solution $(1.52 \mathrm{mg}$ protein $/ \mathrm{mL})$ at $30^{\circ} \mathrm{C}$ under a magnetic stirring condition. After $30 \mathrm{~min}$ of stirring, the mixture was centrifuged and washed three times with phosphate buffered saline (PBS). The obtained solid (named as CALB@MWCNTs) was freeze-dried and stored at $4{ }^{\circ} \mathrm{C}$ until it was used. The amount of the enzyme protein loaded on the CALB@MWCNTs was approximately $30.1 \mathrm{mg}$ protein $/ \mathrm{g}$, as measured through the Bradford method [32].

For preparation of the Pickering emulsions, $15 \mathrm{mg}$ of CALB@MWCNTs was added into $5 \mathrm{~mL}$ of heptane, and then the mixture was homogenized with an ultrasonic cell disruptor (BILON-250Y) for $10 \mathrm{~min}$, operating at $12 \mathrm{~W}$ with 1 -s intervals every $3 \mathrm{~s}$. Then, $1 \mathrm{~mL}$ of PBS (10 mM, pH 7.0) was added to the above suspension liquid and it was ultrasonically emulsified for 5 min to obtain a black emulsion. Then, the biocatalytic Pickering emulsion, stabilized by the CALB@MWCNTs, was obtained and named CALB @PE.

The esterification of 1-hexanol and hexanoic acid was employed to measure the catalytic performance of CALB@PE. Typically, $2 \mathrm{mmol}$ of 1-hexanol and hexanoic acid were added to $5 \mathrm{~mL}$ of CALB@PE, and then it was incubated in a shaking bath $(150 \mathrm{r} / \mathrm{min})$ at $27^{\circ} \mathrm{C}$. For determining the produced hexylhexanoate concentration, a $1.5-\mu \mathrm{L}$ aliquot of the supernatant solution was removed after $30 \mathrm{~min}$ and was analyzed by an Agilent GC (GC-7090A) equipped with a flame ionization detector (FID) and an SE-30 capillary column $(30 \mathrm{~m} \times 0.25 \mathrm{~mm} \times 0.25 \mathrm{~mm})($ ZKAT Analytical Technology Co., Lanzhou, China). Initially, the column temperature was constant at $80^{\circ} \mathrm{C}$ for $0.5 \mathrm{~min}$, was then heated to $170{ }^{\circ} \mathrm{C}$ at $20{ }^{\circ} \mathrm{C} \mathrm{min}-1$, and then was heated up to $200{ }^{\circ} \mathrm{C}$ within $6 \mathrm{~min}$. The temperature of the 
sampler and the detector temperature were set at $230{ }^{\circ} \mathrm{C}$. All reactions were tested in parallel three times. Enzyme activity $(1 \mathrm{U})$ was defined as the amount of enzyme that was needed to produce $1 \mu \mathrm{mol}$ hexylhexanoate per min.

The effect of the preparation parameters, including the dosage of the CALB@MWCNTs and the emulsification time, on the activity of CALB@PE was investigated. The thermal stability of CALB@PE was also analyzed by measuring the activity change after being incubated in water baths of different temperatures $\left(20-60^{\circ} \mathrm{C}\right)$ for $3 \mathrm{~h}$.

\subsection{Characterization}

A light microscope was used to observe the CALB@PE morphology, and the average droplet diameters were measured using the statistical analysis of over 100 droplets. A Nova Nano SEM 450 field-emission microscope was operated to analyze the microscopic characteristics of the CALB@PE droplets. Confocal laser scanning microscopy (CLSM) micrographs were recorded on a Leica TCS SP5 optical microscope. FITC-Dex and Nile Red were used as fluorescent indicators.

\subsection{Synthesis of Biodiesel}

The biodiesel production was performed in 15-mL pressure flasks, containing $5 \mathrm{~mL}$ of CALB@PE (the dosage of CALB@MWCNTs was $20 \mathrm{mg}, 40 \mathrm{mg}, 60 \mathrm{mg}, 80 \mathrm{mg}, 100 \mathrm{mg}, 120 \mathrm{mg}$, and $140 \mathrm{mg}$ ). J. curcas L. seed oil (1.5 g) and methanol mixtures (molar ratios of methanol to oil were 1:1, 2:1, 3:1, 4:1, $5: 1,6: 1$, and $7: 1)$ were used as substrates. The flasks were incubated at certain temperatures $(30,35,40$, 45 , and $\left.50^{\circ} \mathrm{C}\right)$ and were shaken in a thermostatic shaking water bath $(150 \mathrm{r} / \mathrm{min})$. The biodiesel yield was measured by gas chromatography (GC) equipped with an FID and SE-30 capillary column [24]. Nitrogen gas was used as the carrier, and the flowrate was $20 \mathrm{~mL} / \mathrm{min}$. The GC column was constant at $160^{\circ} \mathrm{C}$ for $2 \mathrm{~min}$ and was heated to $220^{\circ} \mathrm{C}$ at $15^{\circ} \mathrm{C} \mathrm{min}-1$. Then, the temperature rose to $260^{\circ} \mathrm{C}$ within $5 \mathrm{~min}$ and was maintained for $10 \mathrm{~min}$. The temperature of the sampler and the detector temperature were set to $230{ }^{\circ} \mathrm{C}$ and $285^{\circ} \mathrm{C}$, respectively. The sample was composed of the reaction mixture, $\mathrm{n}$-hexane and salicylate acid methyl ester, mixed at a volume ratio of 1:1:2, and each sample was tested three times to obtain accurate results. The optimum production conditions were analyzed using single-factor experiments and RSM.

The reusability of CALB@PE was assessed by measuring the residual catalytic activity after each cycle of the reaction. After the completion of the reaction, the reaction system was demulsified by centrifugation and returned to a biphasic state. Then, the upper layer of heptane (containing the products) and the water (containing unreacted methanol) were collected by a liquid transfer. The CALB@MWCNTs, after washing with PBS three times, were directly used to form the new CALB@PE, as described above, and were then used to catalyze the next cycle of biodiesel production with fresh substrates.

\section{Conclusions}

In this study, a robust biocatalyst system of CALB@PE-based Pickering emulsions was constructed and characterized by SEM, CLSM, and optical microscopy. Then, the CALB@PE was employed to catalyze biodiesel production from J. curcas L. seed oil. The CCD-RSM method was conducted to study the effect of the methanol/oil molar ratio, the CALB@PE dosage, the temperature, and the reaction time on the esterification and transesterification of the J. curcas L. seed oil with methanol. The maximum yield of biodiesel reached $95.2 \%$ under the optimal reaction conditions of the amount of J. curcas $\mathrm{L}$. seed oil of $1.5 \mathrm{~g}$, methanol/oil molar ratio of 4.64:1, CALB@PE dosage of $106.87 \mathrm{mg}$, temperature of $34.9^{\circ} \mathrm{C}$, and reaction time of $11.06 \mathrm{~h}$. CALB@PE exhibited better reusability than that of Novozym 435 when directly compared in the process of biodiesel production.

Supplementary Materials: The following are available online at http:/ / www.mdpi.com/2073-4344/8/12/587/s1, Figure S1. The relationship between the distribution of emulsion size and the dosage of CALB@MWCNTs, Figure S2. The images of CALB@PE with different CALB@MWCNTs dosage (a: 1\%, b: 1.5\%, c: 2.0\%, d: 3.0\%, e: 
4.0\%, f: 5.0\%, g: 6.0\%), Figure S3. The images of CALB@PE with different ultrasonic emulsification time (a: 0min, b: $5 \mathrm{~min}, \mathrm{c:} 10 \mathrm{~min}, \mathrm{~d}: 15 \mathrm{~min}$, e: $20 \mathrm{~min}$ ), Figure S4. The interaction between the distribution of emulsion size and ultrasonic emulsification time. Table S1. Comparison of the performance of CALB@PE with other enzyme catalysts in biodiesel production.

Author Contributions: Conceptualization, Y.J. and J.G.; Data curation, X.L.; Funding acquisition, J.G.; Investigation, L.W. and X.L.; Project administration, L.W. and Y.J.; Resources, L.W.; Software, X.L.; Writing—original draft, L.Z.; Writing—review \& editing, L.M. and Y.H.

Funding: This research and the APC were both funded by the Tianjin Jinnan District Science and Technology Project (grant number: 20161515).

Acknowledgments: This work was supported by the Tianjin Jinnan District Science and Technology Project (grant number: 20161515).

Conflicts of Interest: The authors declare no conflict of interest.

\section{References}

1. Silitonga, A.S.; Atabani, A.E.; Mahlia, T.M.I.; Masjuki, H.H.; Badruddin, I.A.; Mekhilef, S. A review on prospect of Jatropha curcas for biodiesel in Indonesia. Renew. Sustain. Energy Rev. 2011, 15, 3733-3756. [CrossRef]

2. Christopher, L.P.; Kumar, H.; Zambare, V.P. Enzymatic biodiesel: Challenges and opportunities. Appl. Energy 2014, 119, 497-520. [CrossRef]

3. Kim, K.H.; Lee, O.K.; Lee, E.Y. Nano-Immobilized Biocatalysts for Biodiesel Production from Renewable and Sustainable Resources. Catalysts 2018, 8, 68. [CrossRef]

4. Qian, J.; Wang, F.; Liu, S.; Yun, Z. In situ alkaline transesterification of cottonseed oil for production of biodiesel and nontoxic cottonseed meal. Bioresour. Technol. 2008, 99, 9009-9012. [CrossRef] [PubMed]

5. Shi, J.F.; Wang, X.L.; Zhang, S.H.; Tan, L.; Jiang, Z.Y. Enzyme-conjugated ZIF-8 particles as efficient and stable Pickering interfacial biocatalysts for biphasic biocatalysis. J. Mater. Chem. B 2016, 4, 2654-2661. [CrossRef]

6. Li, J.; Li, L.; Tong, J.; Wang, Y.; Chen, S. Research Development on Lipase-catalyzed Biodiesel. Energy Procedia 2012, 16, 1014-1021. [CrossRef]

7. Ying, H.; Zhang, L.; Wu, D.; Lei, Q.; Guo, Y.; Fang, W. Ionic strength-response hyperbranched polyglycerol/polyacrylic acid hydrogel for the reversible immobilization of enzyme and the synthesis of biodiesel. Energy Convers. Manag. 2017, 144, 303-311. [CrossRef]

8. Zhou, Z.; Inayat, A.; Schwieger, W.; Hartmann, M. Improved activity and stability of lipase immobilized in cage-like large pore mesoporous organosilicas. Microporous Mesoporous Mater. 2012, 154, 133-141. [CrossRef]

9. Adnan, M.; Li, K.; Xu, L.; Yan, Y. X-Shaped ZIF-8 for Immobilization Rhizomucor miehei Lipase via Encapsulation and Its Application toward Biodiesel Production. Catalysts 2018, 8, 96. [CrossRef]

10. You, Q.; Yin, X.; Zhao, Y.; Zhang, Y. Biodiesel production from jatropha oil catalyzed by immobilized Burkholderia cepacia lipase on modified attapulgite. Bioresour. Technol. 2013, 148, 202-207. [CrossRef] [PubMed]

11. Nguyen, C.H.; Liang, S.H.; Doan, T.T.; Su, C.H.; Yang, P.C. Lipase-catalyzed synthesis of biodiesel from black soldier fly (Hermetica illucens): Optimization by using response surface methodology. Energy Convers. Manag. 2017, 145, 335-342. [CrossRef]

12. Yan, Y.; Miao, J.; Yang, Z.; Xiao, F.X.; Yang, H.B.; Liu, B.; Yang, Y. Carbon nanotube catalysts: Recent advances in synthesis, characterization and applications. Chem. Soc. Rev. 2015, 44, 3295-3346. [CrossRef] [PubMed]

13. Prlainović, N.Ž.; Bezbradica, D.I.; Knežević-Jugović, Z.D.; Stevanović, S.I.; Avramov Ivić, M.L.; Uskoković, P.S.; Mijin, D.Ž. Adsorption of lipase from Candida rugosa on multi walled carbon nanotubes. J. Ind. Eng. Chem. 2013, 19, 279-285. [CrossRef]

14. Fan, Y.; Wu, G.; Su, F.; Li, K.; Xu, L.; Han, X.; Yan, Y. Lipase oriented-immobilized on dendrimer-coated magnetic multi-walled carbon nanotubes toward catalyzing biodiesel production from waste vegetable oil. Fuel 2016, 178, 172-178. [CrossRef]

15. Liu, J.; Lan, G.J.; Peng, J.; Li, Y.; Li, C.; Yang, Q.H. Enzyme Confined in Silica-based Nanocages for Biocatalysis in Pickering Emulsion. Chem. Commun. 2013, 49, 9558-9560. [CrossRef] [PubMed]

16. Wang, Z.; van Oers, M.C.M.; Rutjes, F.P.J.T.; van Hest, J.C.M. Polymersome Colloidosomes for Enzyme Catalysis in a Biphasic System. Angew. Chem. Int. Ed. 2012, 51, 10746-10750. [CrossRef] [PubMed] 
17. Wu, C.; Kraume, M.; Ansorge-Schumacher, M.B. Optimized Biocatalytically Active Static Emulsions for Organic Synthesis in Nonaqueous Media. ChemCatChem 2011, 3, 1314-1319. [CrossRef]

18. Jiang, H.; Li, Y.; Hong, L.; Ngai, T. Submicron Inverse Pickering Emulsions for Highly Efficient and Recyclable Enzymatic Catalysis. Chem. Asian J. 2018. [CrossRef] [PubMed]

19. Wei, L.; Zhang, M.; Zhang, X.; Xin, H.; Yang, H. Pickering Emulsion as an Efficient Platform for Enzymatic Reactions without Stirring. ACS Sustain. Chem. Eng. 2016, 4, 6838-6843. [CrossRef]

20. Binks, B.P.; Whitby, C.P. Silica Particle-Stabilized Emulsions of Silicone Oil and Water: Aspects of Emulsification. Langmuir 2004, 20, 1130-1137. [CrossRef] [PubMed]

21. Jiang, Y.; Liu, X.; Chen, Y.; Zhou, L.; He, Y.; Ma, L.; Gao, J. Pickering emulsion stabilized by lipase-containing periodic mesoporous organosilica particles: A robust biocatalyst system for biodiesel production. Bioresour. Technol. 2014, 153, 278-283. [CrossRef] [PubMed]

22. Batule, B.S.; Park, K.S.; Kim, M.I.; Park, H.G. Ultrafast sonochemical synthesis of protein-inorganic nanoflowers. Int. J. Nanomed. 2015, 10, 137-142. [CrossRef]

23. Poojari, Y.; Clarson, S.J. Thermal stability of Candida antarctica lipase B immobilized on macroporous acrylic resin particles in organic media. Biocatal. Agric. Biotechnol. 2013, 2, 7-11. [CrossRef]

24. Jiang, Y.; Gu, H.; Zhou, L.; Cui, C.; Gao, J. Novelin SituBatch Reactor with a Facile Catalyst Separation Device for Biodiesel Production. Ind. Eng. Chem. Res. 2012, 51, 14935-14940. [CrossRef]

25. Gu, H.; Jiang, Y.; Zhou, L.; Gao, J. Reactive extraction and in situ self-catalyzed methanolysis of germinated oilseed for biodiesel production. Energy Environ. Sci. 2011, 4, 1337-1344. [CrossRef]

26. Kumar, D.; Nagar, S.; Bhushan, I.; Kumar, L.; Parshad, R.; Gupta, V.K. Covalent immobilization of organic solvent tolerant lipase on aluminum oxide pellets and its potential application in esterification reaction. J. Mol. Catal. B: Enzym. 2013, 87, 51-61. [CrossRef]

27. Liu, L.; Hong, Y.; Ye, X.; Wei, L.; Liao, J.; Huang, X.; Liu, C. Biodiesel production from microbial granules in sequencing batch reactor. Bioresour. Technol. 2018, 249, 908-915. [CrossRef] [PubMed]

28. Babaki, M.; Yousefi, M.; Habibi, Z.; Mohammadi, M. Process optimization for biodiesel production from waste cooking oil using multi-enzyme systems through response surface methodology. Renew. Energy 2017, 105, 465-472. [CrossRef]

29. Sivaramakrishnan, R.; Muthukumar, K. Production of methyl ester from oedogonium sp. oil using immobilized isolated novel Bacillus sp. lipase. Energy Fuels 2012, 26, 6387-6392. [CrossRef]

30. Zhou, Z.; Piepenbreier, F.; Marthala, V.R.R.; Karbacher, K.; Hartmann, M. Immobilization of lipase in cage-type mesoporous organosilicas via covalent bonding and crosslinking. Catal. Today 2015, 243, 173-183. [CrossRef]

31. Wu, C.; Bai, S.; Ansorge-Schumacher, M.B.; Wang, D. Nanoparticle Cages for Enzyme Catalysis in Organic Media. Adv. Mater. 2011, 23, 5694-5699. [CrossRef] [PubMed]

32. Gao, J.; Wang, Y.; Du, Y.; Zhou, L.; He, Y.; Ma, L.; Yin, L.; Kong, W.; Jiang, Y. Construction of biocatalytic colloidosome using lipase-containing dendritic mesoporous silica nanospheres for enhanced enzyme catalysis. Chem. Eng. J. 2017, 317, 175-186. [CrossRef]

(C) 2018 by the authors. Licensee MDPI, Basel, Switzerland. This article is an open access article distributed under the terms and conditions of the Creative Commons Attribution (CC BY) license (http://creativecommons.org/licenses/by/4.0/). 